\title{
A comparison of the effects of intermittent versus continuous exercise on blood glucose control in individuals with Type 1 Diabetes
}

\author{
David Archer, Craig Newby, Beth Allan and Leuenberger Thomas \\ School of Nursing and Health Sciences, University of Sunderland, Sunderland, United Kingdom
}

\section{Abstract}

Exercise has many health benefits for individuals with Type 1 Diabetes (T1D), however it carries the risk of hypoglycaemia. Research has indicated that intermittent high intensity exercise reduces this risk compared to steady state exercise, potentially via a greater anaerobic component inducing increased lactate and catecholamine response.Six physically active males aged $23 \pm 5$ years, BMI $24.9 \pm 1.8 \mathrm{~kg}^{-2}, \mathrm{Vo}_{2} \max 47.9 \pm 10.1 \mathrm{ml} \mathrm{kg}^{-1} \bullet \mathrm{min}^{-1}$ diagnosed with Type 1 Diabetes for $9 \pm 3$ years and a $\mathrm{HbA}_{1 \mathrm{c}}$ concentration of $8.6 \pm 0.3 \%$ participated in a randomised counterbalanced trial. Participants exercised for 60 min on a cycle ergometer on two occasions separated by 7 days, which consisted of a moderate continuous steady state exercise session at $40 \% \mathrm{O}_{2}$ max (CONT), or the same exercise intensity interspersed with $7 \mathrm{~s}$ high intensity sprints at $100 \% \mathrm{Vo}_{2}$ max every 2 min (INT). Blood glucose concentration was assessed via capillary blood sampling every 10 min during exercise and at regular intervals in the 60 min post exercise (Accu-Chek Aviva, Roche, UK). Additional metabolic measures such as blood lactate concentration and carbohydrate oxidation rates were assessed during exercise. Participants ingested small quantities of a carbohydrate drink, if required, to avoid hypoglycaemia during exercise. Magnitude based inferences were used to compare the two exercise trials and Effect Sizes (ES) calculated using Cohen's d and results presented as mean \pm SD.Average blood glucose concentration was lower on the INT trial compared to CONT during both the exercise phase $\left(8.9 \pm 1.7 \mathrm{mmol}^{-1}\right.$ vs $7.1 \pm 1.1 \mathrm{mmol}^{-1}$; ES 0.55$)$ and the $60 \mathrm{~min}$ post-exercise recovery phase $\left(8.1 \pm 1.9 \mathrm{mmol}^{-1} \mathrm{vs}^{-1}\right.$ $7.0 \pm 1.8 \mathrm{mmol}^{-1}{ }^{-1}$; ES 0.56). Carbohydrate oxidation was greater on the INT trial compared to CONT $\left(1.9 \pm 1.4 \mathrm{~g}^{\circ} \mathrm{min}^{-1} \mathrm{vs} 1.5 \pm 0.6\right.$

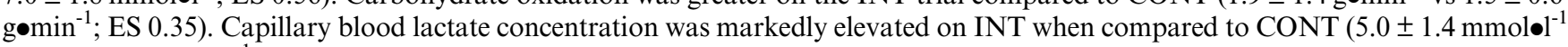
vs $2.4 \pm 1.1 \mathrm{mmol}^{-1} \mathrm{l}^{-1}$; ES 2.48). Carbohydrate ingestion during exercise was $13 \pm 11 \mathrm{~g}$ and differed little between trials (ES 0.18 ). Despite greater anaerobic metabolic response, the addition of intermittent high intensity sprints to 60 min steady-state cycle exercise resulted in greater declines in blood glucose concentration during the exercise and post-exercise period, potentially by inhibition of the counter regulatory hormone response expected on the INT trial. These results would indicate that additional exogenous carbohydrate ingestion may be required for individuals with T1D when intermittent sprints are added to prolonged continuous exercise.

\section{Conflict of Interest}

There is no conflict of interest 